\title{
N1 Sleep to Total Sleep Time Ratio Measurement
}

National Cancer Institute

\section{Source}

National Cancer Institute. N1 Sleep to Total Sleep Time Ratio Measurement. NCI

Thesaurus. Code C156555.

The determination of the ratio of $\mathrm{N} 1$ sleep time compared to total sleep time. The measurement may be expressed as a ratio or percentage. 